\title{
THE REGRESS CHALLENGE, INFINITISM AND RATIONAL DIALECTICS
}

\author{
Husein Inusah \\ University of Cape Coast, Ghana
}

\begin{abstract}
I argue in this paper that infinitism is the best answer to the dialectical regress challenge. Infinitism, as a theory of rational dialectics, has not received enough attention from scholars because major proponents of the theory have focused mainly on using infinitism to answer an epistemic regress problem. Rather than construing infinitism as an answer to the epistemic regress question, I take the theory to be addressing a dialectical regress challenge and subsequently pitch it against its dialectical rivals. It emerges that dialectical infinitism addresses the regress challenge far better than its competitors if it is couched as a social contextualist thesis.
\end{abstract}

\section{INTRODUCTION}

I argue in this essay that infinitism outshines its dialectical rivals: foundationalism and egalitarianism. I begin by giving a brief account of scepticism, highlighting how the corollary of certain forms of scepticism leads to the regress challenge. Next, I discuss in detail the two formulations of the regress question, namely the dialectical and the epistemic regress, and argue that using the dialectical form of the regress to motivate a kind of foundationalism is not enough of a requirement for answering the dialectical regress challenge. Furthermore, I show that a related view, dialectical egalitarianism, including some extant versions of infinitism, fails to address the regress challenge adequately. I conclude that infinitism provides a promising alternative to solving the dialectical regress challenge if couched as a socially contextualist thesis.

\section{THE REGRESS PROBLEM}

Sextus Empiricus is usually credited as the chief proponent of justification scepticism. ${ }^{1}$ The writings of Sextus Empiricus started the sceptical view of the Pyrrhonian found in the Five Modes of Agrippa. The Pyrrhonian sceptics question whether any belief can be proven because any proof must be proven by another proof, which must itself be proven by another proof, and so on ad infinitum. The argument 
couched in simple terms is that no human being can adduce infinite justification for a belief and still be justified in believing the proposition taking cognisance of the fact that any reason adduced for the justification of a belief itself needs a reason for its justification and so on. Here, Sextus invites us to consider the following argument:

...the Mode based upon regress ad infinitum is that whereby we assert that the thing adduced as a proof of the matter proposed needs a further proof, and this again another, and so on ad infinitum, so that the consequence is suspension, as we possess no starting point for our argument (Empiricus 1995, 86).

As shown in the foregoing, by conceding our inability to cite reasons for every reason for the justification of the proposition we hold, the Pyrrhonian sceptics suggest that we suspend judgement - we should refuse to assent or dissent to believing any proposition no matter how good our reasons are. Here, the Pyrrhonian problematic is couched in the form of a sceptical challenge purporting to show that finite beings cannot have justified beliefs. Therefore, we should suspend judgement about all our knowledge claims. This is the argument for the infinite regress of reasons known as the regress argument. Here, one notices that the regress argument is formulated in the form of a challenge, namely no human being can offer an infinite and a non-repeating series of reasons to justify a given proposition without running into a vicious regress. ${ }^{2}$ In other words, a subject cannot offer infinitely many reasons in support of a belief or have her belief justified by an infinite chain of reasons and still be justified in believing the proposition in question. In the former case, the subject will have to cite a reason for every reason in the series of justified reasons to show that she is justified and in the latter case, the subject's belief will be justified by an infinite series of justified reasons which, according to the sceptics, is practically untenable. The sceptics then conclude that one cannot have a justified belief.

\section{EPISTEMIC AND DIALECTICAL REGRESS}

The regress is said to come in two versions: epistemic and dialectical regress (Alston 1989, 26-32; Audi 1993, 118-120 and Rescorla 2009, 43). The epistemic regress involves questioning what justifies a given belief, and the dialectical regress involves challenging a subject's justified belief (Rescorla 2009, 44). The epistemic regress is said to involve the structure of justification and concerns what conditions justify a given belief. These conditions are believed to be certain perceptual experiences that provide incorrigible or prima facie justification for associated beliefs. Alston (1989), Audi (1993), Peacocke (2004), Pryor (2000) and many others have articulated different defence of this view.

In contrast, the dialectical regress does not concern the structure of epistemic justification; rather, it concerns the structure of rational dialectic. The dialectical form of the regress requires solving the regress problem by mobilising an argument to defend one's claim. However, an answer to the structural regress requires that there is an answer, and this answer is cited in the proposition that constitutes the answer. 
Each of the structural and the dialectical forms of the regress comes with its strengths and weaknesses. I do not intend to discuss the controversy regarding which form of the regress is more plausible than the other. This is because, as Audi (1993, 123) argues, "the dialectical and the structural formulations of the regress problem are significantly different", and one's preferable choice will depend on the theory of justification being defended. Audi $(1993,12)$ however, notes that "the dialectical regress favours a non-foundationalism." 3 while the structural regress favours epistemic foundationalism. Partly ${ }^{4}$ in line with Audi's thought and for the purpose of this study, I couch the regress question in the form of a dialectical challenge. ${ }^{5}$

1. To show that you are justified in believing $p$ requires citing a supporting reason for your proposition $p$.

2. For every supporting reason cited in defence of $p$, you must be able to cite another reason, $\mathrm{r} 2$, such that $\mathrm{r} 2$ is a justified and undefeated reason for $\mathrm{r} 1$, $\mathrm{r} 3$ is a justified and undefeated reason for $\mathrm{r} 2$ and so on, ad infinitum.

3. Therefore, to show that you are justified, you must show that you can cite an infinite series of supporting reasons for $p$.

4. Human beings are not able to show that they are justified with infinitely many reasons.

5. Therefore, it is not possible to show that one has a justified belief.

A quick review of how dialectical theories of justification endorse the above argument is appropriate. Dialectical foundationalists accept premise 1 of the regress argument because they believe that the activity of justifying requires citing a supporting reason for any proposition believed. However, they reject premise 2 on the basis that certain beliefs have a default status and serve as regress stoppers within the activity of asking and giving reasons. The egalitarian and the infinitist accounts are based on premise 3 because both views endorse the idea that the activity of justifying requires that a subject be able and willing to cite infinitely many reasons in support of any proposition believed. However, infinitists deny premise 4 on the basis that human beings can show they are justified in believing a proposition with infinitely many reasons. Granted, I provide a brief survey of a few versions of dialectical foundationalism and egalitarianism before critiquing these views.

\section{DIALECTICAL FOUNDATIONALISM}

To solve the problem of the regress of justification, Robert Brandom (1994, 177) presents what he calls the "default and challenge structure" of entitlement. Roughly, the crux of the idea is that the regress question arises from the questionable premise that entitlement can be attributed only if it is demonstrated. However, when we consider entitlement as a status we can have by default, that is, the idea that we can be entitled to a proposition without having to demonstrate our entitlement, the regress question disappears. Hence, all entitlements eventually go back to a default entitlement. No commitment, whether inferentially or deferentially justified, is 
justified unless it is based on default entitlement. Brandom $(1994,178)$ remarks: "there is no fixed point in advance where demands for justification or demonstration of entitlement come to an end, but there are enough places where such demands can end that there need be no global threat of debilitating regress." According to Brandom $(1994,222)$, there are two sorts of entitlements that meet the requirements as default entitlement. The first is certain sentence types that are treated as "free moves" by the members of a speech community. These sentence types are accorded a default justificatory role and treated as prima facie justified first premises because they are nearly trivial commonplaces. The second types of sentences are observational sentences or non-inferential reports. He describes a non-inferential report as an assertion treated by an attributor as a claim the reporter is entitled to just in case the attributor takes the reporter to be a reliable observer under certain observing conditions. $^{6}$

Michael Williams $(1999 ; 2001 \& 2004)^{7}$ suggests a similar solution to the regress of justification. He terms his view the "default and challenge" model of justification. Roughly, the view is that regress of justification comes to an end as long as there are no justified challenges to the belief terminating the regress in an array of justified reasons. The point is that in the absence of defeaters, beliefs are justified by default, and these beliefs serve as the bedrock upon which other beliefs in the series of justified reasons rest. The reason is that "appropriate defeaters cite reasonable and relevant error possibilities" (Williams 2001, 149).

The third stripe of dialectical foundationalism is Adam Leite's model of justification that he calls a 'localist solution' to the regress of justification. Roughly, the view is that to justify and be justified in holding a given proposition, requires one to draw on the appropriately justified background proposition to provide good reasons for holding the proposition (Leite 2005, 395). Leite conceives justification as a matter of giving and asking of reasons where the justificatory status of a subject's proposition bears upon how the person defends the proposition in question. According to Leite, citing reasons in defence of a belief one holds is showing that the belief is responsibly held. Moreover, if a subject is unable to offer or cite reasons to defend a belief, then the person is not justified in holding that belief. Thus, from Leite's perspective, our ordinary practice of evaluating our beliefs should be guided by a norm demanding from us the ability to provide good reasons for holding beliefs. However, the activity of justifying a belief has what he calls a local structure which requires a person to defend a single belief or a limited set of beliefs with non-repeated reasons drawn from one's background beliefs.

\section{Dialectical Foundationalist Reply to the Regress Problem}

Before I proceed, I will first rehearse the common features of the versions of dialectical foundationalism adumbrated above. The versions of dialectical foundationalism espoused in the foregoing share the conviction that the practice of justifying and being justified in believing a proposition involves the activity of asking and giving of reasons in support of one's proposition. They also share the view that though justification involves a game of asking and giving of reasons, the activity of 
justification comes to an end. ${ }^{8}$ Questions involving justification thus have a stopping point, a point where certain beliefs (you could call them dialectically basic beliefs) halt the regress of justification.

If so, let us consider the regress argument above. We realise that the dialectical foundationalists accept premise 1 . The issue with premise 1 is that for one to show that she is justified in believing $p$ requires her to cite reasons in support of $p$. The motive for accepting premise 1 is to endorse the view that the process of justifying a proposition requires that one must be able to cite a reason in support of what she believes. At the same time, the dialectical foundationalists are wont to concede that there are dialectically basic beliefs or propositions, which could stop the regress of justification without demanding any further reasons for its justification and by so doing rejecting premise 2 . But are the dialectical foundationalists not committing a mistake? The sort of reasoning embedded in this kind of thinking appears as the following: ' $p$ is justified, but I cannot show why $p$ '. However, if we construe justification as a game of giving and asking of reasons, we will see that it appears arbitrary to stop giving out reasons.

One may argue that an interlocutor can stop demanding for reasons, and in those cases, a subject is not obliged to answer any more questions. However, such a strategy is misplaced. The point is that once we conceive justification as an act of asking and giving of reasons, we should be ready to answer all questions in defence of our beliefs. The truth is that there are no final questions. If there are no final questions, then there are no final answers. Therefore, the activity of justifying has no permanent stopping place.

Consequently, the dialectical foundationalists, although accept premise 1 , are also willing to concede the point that some beliefs require no reasons for their justification. So, the strategy is to assume that other beliefs have default status (whatever that might be) as their reasons to avoid a vicious regress. But why should that be a basis for subscribing to the activity of inferential justification in the first place? The point here is that the dialectical foundationalist appears to cobble together both the epistemic and the dialectical formulations of the regress questions. Their main target seems to be that they are answering the dialectical regress question when they subscribe to the activity of justifying yet they also subscribe to the epistemic formulation of the regress question by the postulation that there are beliefs justified by default.

Now let us consider the prospects of dialectical foundationalism against the sceptical question. Consider the regress argument above. The motive for the regress argument is to show that it is impossible to cite infinitely many reasons in support of a proposition and still be justified in holding that proposition. It is couched in the form of a challenge purporting to show that no human being can produce an infinite and a non-repeating series of reasons for a belief and be justified in holding that belief. It appeals to our finite capacity as human beings to discourage us from embarking on such a project. What is the dialectical foundationalist reply to the regress argument? Consider the following line of thought: 
1. For $\mathrm{S}$ to show that she is justified in believing $p$, she must be able to cite a reason in defence of $p$.

2. For every reason cited in defence of $p$ also requires another reason, and that also requires another reason and so on, ad infinitum.

3. Therefore, for $S$ to show that she is justified in believing $p$, she must cite an infinite series of reasons in support of $p$.

4. Human beings are finite beings and are unable to show that they are justified with infinitely many reasons.

5. Therefore, for $S$ to show that she is justified in believing $p$ she must cite a finite series of reasons in defence of $p$.

6. It is humanly possible for $S$ to cite a finite series of reasons in support of $p$.

Therefore, $\mathrm{S}$ can show that she is justified in believing $p$.

The dialectical foundationalists will perhaps argue that this argument motivates their view and use it to knock out rival theories leaving dialectical foundationalism as the only plausible alternative. If the dialectical foundationalist is right, then the sceptical challenge crumbles. However, the dialectical foundationalist answer is not adequate for solving the dialectical regress question. An implicit idea behind the regress argument is simply the following: when a belief put forward as a claim to knowledge is challenged, we should advance reasons in the belief's support and reasons for those reasons and so on. Construing this to be humanly impossible, the sceptics conclude that since we cannot offer reasons infinitely in support of our beliefs, we cannot have justified beliefs. The dialectical foundationalists agree with the sceptics that we cannot offer an infinite series of reasons for any proposition believed because we are finite beings, thus approving premise 4 of the dialectical regress argument. However, she disagrees with the sceptical conclusion that we cannot have a justified belief. The issue is that once the dialectical regress argument is construed to mean that the process of justification involves showing that one is justified, then she has not met the requirement for justification if she allows some beliefs to possess default justificatory status.

The core problem the dialectical foundationalist seems not to pay heed to is that in providing a foundation for series of justified reasons, she is inadvertently drawing limits on our ability to offer reasons for our beliefs which runs contrary to her initial idea that justification is a game of asking and giving of reasons. Thus, the dialectical foundationalist appears to argue that in the course of offering reasons for our beliefs, we give up as we encounter these sorts of default justified propositions. In other words, we give up on the idea of dialectical interaction and embrace the same sceptical question that we profess to answer, namely that inferential knowledge is impossible because of our finite human capacity. This way of looking at things renders the dialectical foundationalist claim self-defeatist. The dialectical foundationalist may have denied the sceptical conclusion that we cannot have justified belief, by postulating default justificatory beliefs, but that is not grounds enough for showing that one is justified. If showing that one is justified requires citing a justificatory supporting reason for a proposition, then one can only be justified if she were to show that she is 
justified by citing a reason in defence of her proposition. However, by citing a stopping point for the regress, the dialectical foundationalist is no more showing that she is justified, she is just assuming that she is, ipse dixit. This consideration makes the dialectical foundationalists eschew the vital question at hand: the idea of showing that one is justified in order to hold a justified belief and to avoid dogmatism. ${ }^{9}$

I contend that the sceptical challenge calls for a dialectical theory of justification that can provide an infinite and a non-repeating chain of reasons in defence of a proposition without running into a vicious regress - meaning that the challenge calls for a robust theory that could meet the regress question head-on. In other words, it needs a reply that does not evade the regress question. The dialectical foundationalist misses the issues outright by invoking 'unexplained' restrictions on certain beliefs considered to offer a terminating point for the regress whereas the problem posed by the regress is to question whatever beliefs we hold to avoid dogmatism. A viable reply to the regress problem will be a theory that can provide an infinite series of genuine justification without running into a vicious regress.

\section{DIALECTICAL EGALITARIANISM}

Dialectical egalitarianism is the view that in the activity of asking and giving of reasons, all reasons adduced in defence of a given proposition require further reasons. ${ }^{10}$ Dialectical egalitarianism is different from dialectical foundationalism on the ground that it does not stipulate any dialectically basic belief to stop the regress of justification. When faced with a persistent interlocutor, every reason cited in support of a proposition requires further reason. There is no proposition endowed with any privileged or default role in a series of justified reasons. In other words, there are no regress stoppers or resting points in the game of asking and giving of reasons.

A recent advocate of the theory is Michael Rescorla. He lists other proponents of egalitarianism to include the Pyrrhonian sceptics, Neurath (1959), Klein (1999, 2003) and Van Eemeren and Grootendorst (2004). According to Rescorla $(2009,46)$, the motivation for egalitarianism is to avoid dogmatism. Egalitarians appear to endorse the view that in the process of justifying a given belief, it seems arbitrary and dogmatic to stop giving reasons in defence of the belief. To refrain from the activity of justifying is tantamount to subscribing to dogmatism or breaching the rules of reasoned discourse which is the criterion through which we rationally evaluate propositions when providing one another with arguments and counter-arguments (Rescorla 2009).

Most often, scholars leaning against dialectical egalitarianism use it to motivate other theories of justification or scepticism. For instance, the Pyrrhonian sceptic uses it to motivate scepticism about justification and knowledge to induce suspension of judgement. Infinitists also employ dialectical egalitarianism to motivate their theory. Infinitists argue that epistemic justification is infinite and that there is no stopping point in the game of giving and asking of reasons. It appears from this infinitist standpoint that infinitism and egalitarianism share much common ground. However, there is an inherent difference that I will address shortly. 


\section{Egalitarian Reply to Regress Problem}

Recall the sceptical challenge that it is not possible for human beings to cite an infinite series of reasons in defence of a proposition to have justified beliefs. The sceptical argument is primarily based on the infinitist lemma to drive home two principal claims against the concepts of justification and knowledge. Firstly, the sceptic argues that if justifying propositions themselves require reasons for their justification, then no finite being can achieve this feat. The reason is that one has to cite an infinite series of reasons in support of a proposition which is not a possible mission for finite beings like us to undertake. This claim cites our inability to offer an infinite series of reasons in support of a proposition we hold. The second claim rides on the back of the first. If human beings cannot cite infinite reasons to justify propositions they hold, then justification is not possible. Hence, it is humanly impossible to show that we have justified beliefs.

The egalitarian thesis appears to endorse as well as answer the first claim but neglects the second. Egalitarians argue that it is possible to keep citing reasons for every proposition in an infinite series and therefore reject premise four of the regress argument. However, they do not say anything much about the conclusion of the argument, namely whether one can show that she is justified in holding a proposition with infinite beliefs. Human beings can indeed cite infinitely many reasons in defence of a proposition. But for what purpose? To achieve infinite justification, like the infinitist, or to suspend judgement, like the Pyrrhonians? This is the point where infinitism part ways with egalitarianism - infinitists answer the sceptical question from the point of responding to the sceptical avowal of our inability to offer infinite series of reasons in support of a proposition, to the claim that it is humanly impossible to have justified beliefs.

\section{Infinitist Reply to the Regress Problem}

Infinitism is the view that the process of justification is infinite and nonrepeating. Infinitists hold that for a subject to be completely justified in believing that $p$, it is necessary that she can cite an infinite and a non-repeating series of justified reasons in defence of $p$. As I have shown, if any theory should be plausible at all as a satisfactory reply to the regress problem, it needs to be tested on how it handles the sceptical challenge posed in the regress problem. Infinitism appears most promising in that regard, taking cognisance of the fact that the theory meets the sceptical challenge head-on. Unlike dialectical foundationalism and egalitarianism, infinitism answers the regress question in a manner that confronts the sceptics directly without evading the regress question.

However, current versions of the theory fail to offer satisfactory answers to two crucial questions emerging from the regress argument, namely how justification is possible within an infinite and non-repeating series of reasons for one to surmount premise 4 of the regress argument and how we can delineate whether an infinite series of justified reasons is truth-conducive? 
To the best of my knowledge, Peter Klein (1998, 919; 1999, 299) provides, through a series of papers, ${ }^{11}$ the most detailed extant defence of epistemic infinitism. He defines infinitism as an account of justification that considers the reasons that justify a belief as members of a chain that is infinitely long, non-repeating and subjectively available to the subject. This view has been attacked on the basis that an infinite array of non-repeating series of reasons is not productive of justification (Moser 1985, 115). The implication is that Klein's version of infinitism even though endorses premise 3 of the regress argument, evades premise 4 thereby conceding to the sceptic that human beings are not capable of showing that they are justified in believing a proposition with infinite reasons. It plays into the egalitarian net. Others have argued that the real problem that threatens Klein's infinitism is not the evasion of premise 4 because even if we can satisfy premise 4 , there remains another worry, namely that the regress condition itself cannot explain whether a justified series of reasons is truth-conducive or not (Cling 2004, 110-111; Aikin 2011, 103).

This criticism fails on two grounds. First, it deploys an epistemic criticism against a dialectical solution to the regress question. It takes infinitism to be answering an epistemic regress question. In contrast to what I have pointed out, the structural regress is devoted to the issue of what justifies a given belief and this "what" is that which shows the connection between justification and truth. Infinitism concerns the structure of rational dialectics and takes the regress question as a challenge that requires the mobilisation of arguments in support of one's claims. Second, any attempt to make infinitism answer this epistemic problem will collapse the theory into a kind of epistemic foundationalism, thereby losing its mooring with the essence of infinitism, which is the avoidance of dogmatism. Cling (2004) acknowledges this constraint on infinitism by arguing that any solution proffered will undermine the purpose of the infinitist regress condition itself; implying that it is impossible to achieve this feat while still being an infinitist. Aikin (2011) later vindicates Cling's assertion when his intervention collapses infinitism into a kind of meta-foundationalism where the infinitist upshot only emerges as a meta-foundational challenge. Now how do we answer premise 4 of the regress challenge to make infinitism justification affording? I propose a model of infinitism I call social contextualist infinitism. I will sketch details of the theory in what follows.

\section{A SOCIAL CONTEXTUALIST INFINITISM}

Contextualism is a nomenclature that is notorious for its diverse meaning. It could either describe a collection of views that emphasis the context in which knowledge ascription is made (See DeRose 1999) or belief is justified (See Annis 1978). Contextualism about knowledge and justification, in very general terms, maintains that whether one knows is relative to a context. It is the view that certain features of contexts, such as the intentions and presuppositions of the members of a conversational context or the verdict of members of a social group, show the standard 
that one must meet for a belief to count as knowledge. The proposal espoused in this essay has a close affinity to the latter conception of contextualism.

In effect, this is the guiding idea of the proposal. It is roughly the view that although an epistemic subject, $S$, can provide an infinite array of reasons for her belief that $p$ at time $t$, the activity of justifying $p$ terminates, albeit tentatively within socially contextualist parameters at time $t$. These parameters endow the terminating belief with an epistemic authority that comprehensively justifies $p$ at time $t$ and at the same time provisionally justifies $S$ 's belief that $p$ which initiates a further regress and subsequently creates room for an infinitist upshot. This is not to suggest that my proposal sanctions any idea of basic belief as the foundationalist endorses: it does not. It only accepts the notion of a social contextualist tentative terminating belief, a view that I espouse shortly in the pages that follow.

Suppose that a subject, $S$, could respond to a sceptical challenge by providing a series of infinite and non-repeating reasons backwards to support a proposition whose truth is in dispute, where her reasons terminate tentatively in standards set by socially contextualist parameters; let us label this notion a socialist contextualist thesis 1 :

$\mathrm{SC} 1$ : A subject, $S$, is justified in believing a proposition, $p$, if and only if (i) $S$ is willing and can provide a potentially infinite and a nonrepeating set of reasons in support of $p$, (ii) $S$ 's series of reasons tentatively terminate at $x$, (iii) $x$ derives a justificatory authority from a social contextualist standard, $y$ and (iv) $y$ partly justifies $S$ in believing $p$.

Perhaps, my use of the expression "social contextualist parameters" is vague and an explanation is pertinent to clarify matters. By "social contextualist parameters" or standards, I mean an epistemic practice sanctioned by one's peers or a community of enquirers. By epistemic practice, I have in mind a sequence of events involving two or more epistemic agents involved in the production of beliefs or other doxastic states. ${ }^{12}$ The crux of my argument is that if the truth of a proposition is in dispute, a subject should be able to draw on the background conception of the epistemic practice of her peers to settle matters and thus to terminate the regress of justification, albeit tentatively. If we are to consider this view, conditions (iii) and (iv) will yield some few objections to SC1.

Firstly, on the social contextualist model of justification, as stipulated by conditions (iii) and (iv), if a subject, $S$, is a smart and a charismatic individual, she could convince her community to endorse a "flagrant fallacy" (Goldman 1997, 155) to sanction her belief that $p$ since her belief requires a justificatory authority from her peers. Here, we are reminded of Goldman's example involving a subject, $S$, who accepts $Y$ as a conclusion based on the premises $W$ and $X$. Meanwhile, her inference from $W$ and $X$ to $Y$ is neither valid nor is a strong inductive inference. Now, if $W$ and $X$ constitute $S$ 's only reasons for believing $Y$, then $S$ is not justified in believing $Y$. But on the interpretation of (iii) and (vi) in $\mathrm{SC} 1$, we can imagine that $S$ is capable of convincing her epistemic peers to accept $Y$ as justified. 
Meanwhile, $S$ herself is not justified in believing $Y$ (Goldman 1997, 157). ${ }^{13}$ However, this counter-example will tell against SC1 only if epistemic justification is construed as a mere game of persuasion. Epistemic justification is not an act of persuasion because it requires a subject to argue that her justification of a belief is not based on wishful thinking, lucky guess or hunch. So, if the epistemic subject is responsible and honest, she will be able to advance good reasons for holding a belief given the background of the justificatory practices endorsed by her peers without endorsing arbitrary belief or circular reasoning or engaging in the act of deception whether knowingly or unknowingly.

Of course, there are scenarios in which some people are notoriously epistemically irresponsible and dishonest. There are also scenarios where some people are dull, unintelligent and uninformed. However, as epistemically responsible agents, we can recognise those who are epistemically dishonest and irresponsible and those who are dull, uninformed or unintelligent. So, a responsible and honest epistemic subject will not indulge in deception or persuade her peers to accept flagrant fallacies or persuade them to accept beliefs she formed in an unreliable manner or an inference she does not believe herself. Hence, thinking that a subject could be epistemically responsible and honest to the justificatory practices endorsed by her community but indulge in the above-listed counter-cases sounds to me absurd. For instance, consider a scenario, where a subject is not mentally derailed or dull or unintelligent or epistemically dubious. Suppose that this subject is well acquainted with the justificatory practices of her community and is completely prepared to engage in the practice with all honesty while in possession of all the background knowledge to participate in this practice correctly. But she later does something to violate her justificatory practice. This will sound incoherent or absurd. In the words of Leite (2005, 406), it is practically incoherent for "someone who, intending to follow the norm does something which - given his background information and competence - he takes the norms to forbid."

However, this intervention does not insulate conditions (iii) and (iv) of SC1 from other criticisms such as the following. Granted that $S$ is an honest and a responsible epistemic subject and completely aware of this, even so, it is not a guarantee to think that her peers or some of her peers possess similar features. Put differently, suppose that $S$ trusts herself as an epistemically credible person, it is still not a good ground to suppose that her trust in her self-reliance about her epistemic capabilities necessarily guarantee trust in her epistemic community. Furthermore, if $S$ trusts her doxastic states that much, why then rely on the judgment of expression of her community for the justification of her belief. Couldn't she as well rely on her epistemic decision-making capabilities to justify her own belief? The first idea questions the credibility of the consensus of one's community about justified belief, i.e., how a community's endorsement of $S$ 's belief endows it with a justificatory authority and the second question concerns the relevance of the social contextualist models of epistemology.

There is a way answers to both matters are related. For instance, matters that lead a subject to rely on the trust of others, while making an inference from her self-trust, for the justification of her belief is germane to the reason why she is likely to rely on 
the trust of others for the justification of her belief. In other words, my willingness to trust other people's epistemic judgment will undoubtedly reveal my preference for a social contextualist justification of the sort I discuss here. However, for clarity sake, I will address these issues separately.

In answering the first question, it is pertinent to note that if a subject has a basic trust in her intellectual faculties, all other things being equal, she should be able to grant trust in the opinions of her community judgement on similar ground. There are possible scenarios that buttress this argument. Suppose that $S$ is a responsible and a conscientious epistemic subject as shown above. It becomes very easy to rely on the trust of another person whom she considers as epistemically competent and perceptually acute. Since $S$ has confidence in her self-trust, she could on similar ground infer that another individual is equally epistemically trustworthy. So, $S$ could tell that this individual has pretty good reasons and her intellectual faculties are as good as hers just by relying on her self-trust.

Having articulated how social contextual parameters are essential to justification, let us turn attention back to our formulation of SC1. As things stand, SC1 does not appear like a plausible infinitist thesis of justification because it evades premise 4 of the regress argument. It states that a subject must articulate her reasons for a belief until she reaches a tentative stopping place, in a belief sanctioned and defined by social standards. However, this tentative terminating belief also partly justifies $S$ in believing $p$. Here, it is tempting not to read 'partly justifies' as partly grounding $p$ in the foundationalist sense of the word.

Moreover, it is cumbersome to articulate a version of infinitism where one's belief is actually justified rather than being provisionally justified. Provisional justification appears to preserve the infinitist thesis leading to the avoidance of dogmatism. So, saying that a proposition is actually justified shuts every door to the belief needing further justification. How can an infinitist theory embrace actual justification and provisional justification in tandem? To shed light on this, it is essential to introduce two salient views about epistemic justification. These views are the synchronic and the diachronic views of epistemic justification.

\section{SYNCHRONIC AND DIACHRONIC VIEWS OF JUSTIFICATION}

Richard Swinburne (2001, 9) defines synchronic and diachronic views of justification as follows:

Theories of justification that analyse what it is for a belief to constitute a justified response to the situation in which the believer finds herself at a given time are called "theories of synchronic justification." And theories "of what it is for a synchronically justified belief to be based on adequate investigation over time" are called "theories of diachronic justification."

In other words, a synchronic view of justification requires of a subject to offer reasons for her beliefs in a single episode, that is, it requires that an epistemic subject 
assesses the content of accepting, rejecting or withholding assent of her belief in a single moment. A dialectical view of synchronic justification demands that a subject assenting to belief $p$ at time $t$, must cite her reasons for $p$ at time $t$ and not later. So, giving one's evidence at time $t$, the proposition $p$ is not justified for $S$ synchronically if $S$ cites her reasons in support of $p$ at a later time. In contrast, diachronic justification is a further enquiry or investigation into a synchronically justified belief. The diachronic view stresses the subject's performance of interrogating a belief over time. It is basically about investigating our beliefs that we hold to be synchronically justified to improve the quality of understanding of the belief in question. So diachronic justification helps us to be better justified about a belief we already hold to be synchronically justified.

A further explanation is that synchronic justification, because it concerns one's commitment to a belief in a single moment, emphasises the product of a dialectical activity of justification in a single episode. For instance, if $S$ 's reasons for believing $p$ terminate in say $q$ in a single episode, $p$ becomes dialectically synchronically justified for $S$ at that material moment. Hence, the series of reasons supporting $p$ becomes the product of the dialectical activity of justifying $p$ at that material moment. In contrast, a diachronic view of dialectical justification emphasises the process of justification. Here, the terminating belief, $q$, though synchronically justified, is nevertheless in the process of justification for diachronic justification.

Two options are available to the dialectical infinitist about the synchronic and the diachronic views of justification:

Synchronic dialectical Infinitism: For a subject $S$ to be justified in believing that $p$ at time $t$, requires that she has cited a potentially infinitely long and non-repeating chain of reasons in support of $p$ at time $t$.

Diachronic dialectical Infinitism: For a subject $S$ to be justified in believing that $p$, requires $S$ to provide a potentially infinitely long and non-repeating chain of reasons for $p$ to the extent that $S$ 's reasons for $p$ also include reasons $S$ has in support of $p$ over time.

Looking at the above formulations, one realises that the diachronic view motivates infinitism because it is an attractive option for an infinitist theory. Its attraction arises from the fact that it takes into consideration the idea that human beings cannot offer infinitely long and non-repeating reasons for their belief in a single episode. So, one's beliefs become synchronically justified as a way of ending the regress tentatively within socially contextualist parameters. However, this synchronically justified belief is further justifiable over time for diachronic justification. The synchronic and the diachronic views of justification combined make available the resources at our disposal in the form of dispositions, as humans, to investigate into our already justified belief to improve our justification of the belief in question better. It is in this sense that infinitism makes sense. Can a proposition which has been already justified synchronically based on the expression of the judgment of 
our community be diachronically justified over time? I think it is within our reach to justify our beliefs in this manner. As Rorty remarks $(1979,159)$ : “it would be foolish to keep the conversation [i.e. "propositions brought-forward-in-defence-of-otherpropositions"] on the subject going once every one, or the majority, or the wise, are satisfied, but of course, we can." We can, not because we can keep citing infinitely many reasons for our beliefs in a single moment; but rather, we can because we have the potential as human beings to form infinitely many beliefs in defence of our already justified belief over time through investigation and inquiry. And these resources are available to us as dispositions or as a kind of mental inclination or a cognitive capability to offer potential reasons for our beliefs.

The reason why diachronic justification motivates infinitism is that it does not stop the infinite regress of justification made possible by the further investigation into a synchronically justified belief, hence helping to avoid dogmatism. The explanation is that inquiry, or the diachronically dialectical activity of justification has no natural stopping point because there are conceivable floodgates of resources available to the subject to pursue further reasons to justify beliefs whose truth is in doubt and these resources, as I argued, are available to the subject in terms of dispositions or cognitive abilities or inclinations. The potential for justification, when conceived this way, is open-ended and can meet a persistent interlocutor's demands for further reasons in support of our beliefs. However, same cannot be said of the process of actually citing reasons loudly in defence of a claim. At least, one might be tired, go hungry or have other engaging commitments at hand. But even so, there seems to be a practical need to stop giving reasons at a point because of the pragmatic burden social contextualist parameter places on us. After all, as finite beings, it is not realistic to cite infinite reasons for the justification for our beliefs because we are finite beings. Therefore, we must make do with what we are presented within a single moment of a dialectical activity of justification. In other words, it is crucial that we accept the product of our series of beliefs that terminate within socially contextualist parameters for actual justification, because that is all we have got to make do with for now, and for provisional justification, because we possess the cognitive inclination to offer potential reasons for these terminating belief in a later time. So, the process of citing reasons finally comes to a halt in a single episode for synchronic justification while we take the synchronic justified belief as standing in need of diachronic justification.

Now how does SC1 fit into my description so far concerning a diachronic view of justification? As things stand, SC1 appeals to only a synchronic view of justification. The explanation is that, by the function of SC1, a subject's series of reasons in defence of $p$ terminate in a social contextualist standard which in turn endows the terminating belief with a certain level of justificatory status, and this partly justifies the subject in holding $p$, I will explain this in a moment. What is obvious with this account is that it allows that the subject's series of beliefs are justified in a single episode. It reveals a tentatively finite justificatory structure of the subject's beliefs. So where does infinitism creep into such a tentative finite structure? Here, the diachronic view provides this missing link. It allows that the subject can provide reasons for her justified reasons over time. It is this process of providing reasons for our already synchronically justified reason that is infinite because there are infinite resources 
available to an epistemic subject to enable her to engage in such infinite investigations to figure out reasons for a yet-to-be justified belief. So, SC1 needs a slight modification to capture the diachronic view of justification vis-a-vis infinitism.

$\mathrm{SC} 1 *$ : A subject, $S$, is justified in believing a proposition, $p$, if and only if (i) $S$ is willing and able to provide a potentially infinite and nonrepeating set of reasons in support of $p$, (ii) $S$ 's series of reasons tentatively terminate at $x$, (iii) $x$ derives a justificatory authority from a social contextualist standard $y$, (iv) $y$ partly justifies $S$ in believing $p$ and (v) $S$ is justified in believing $y$.

From the above construal, (v) delineates a diachronic view of justification. It reveals that $y$ stands to be justified further. It also shows that $y$ is in the process of being justified by $S$. This means that the diachronic view of justification does not show that one has a justified belief but rather indicates that one's belief is in the process of being justified. On this interpretation, we realise that the diachronic view of justification recognises the cognitive abilities available to us to embark on further investigation to better improve the justification of our already synchronically justified belief. So, the synchronic view of justification ensures that we are actually justified for believing a proposition for the time being, and the diachronic view emphasises the infinitely many cognitive resources at our disposal to continually engage in the act of giving and asking of reasons infinitely. If we grant this argument some credibility, then the sceptical regress challenge, namely that human beings are unable to provide infinite reasons for actual justification, can be resolved. In other words, if the sceptical question shows that we are not capable of providing infinite reasons for our beliefs for actual justification as captured in premise 4, we could at least argue that our series of reasons are synchronically justified for actual justification and provisionally justified for diachronic justification, so the challenge throws up by premises 4 is surmounted.

\section{CONCLUSION}

I have shown that dialectical foundationalism, egalitarianism and some extant versions of infinitism do not offer satisfactory answers to the regress of justification. In other words, they evade the contest of meeting the sceptical challenge head-on. Clearly, on this note, infinitism couched as a socially contextualist thesis appears more promising than its dialectical competitors. It is the only response that answers the regress problem satisfactorily. Its virtue lies in the fact that it does not take the regress question for granted. The infinitist response is based on the sceptical lemma, namely that one cannot offer an infinite and a non-repeating series of reasons to justify a proposition. It is this challenge that the version of infinitism espoused here tackles head-on. 


\section{NOTES}

1. However, some have argued that Aristotle rather than Sextus makes the regress problem famous. Aristotle uses the regress to motivate the necessity for first principles. See the 'Posterior Analytic' in Paul K. Moser and Arnold vander Nat (1995).

2. This should not sound as though most infinite regresses are vicious. Others regresses though infinite are virtuous. This view will be made clearer later in the study.

3. What Audi means by non-foundationalism here I presume involves coherentism and infinitism. But also the dialectical construal of the regress problem has been used to defend another type of foundationalism dubbed dialectical foundationalism. Audi does not consider this possibility. The expression dialectical foundationalism appears appropriate to me because it is an option motivated by the dialectical formulation of the regress problem. Others have different labeling for this theory. For instance, Michael Williams calls this version of foundationalism structural or formal foundationalism. See Williams (1996, p. 114). I do not contest any labeling of this theory. I assume that any label one endorses depends on one's interest and purpose.

4. Partly because I also concede that both the structural and the dialectical formulations of the regress problem are worthy of answering but I have only limited myself to the dialectical problem.

5. I modelled this argument on Markus Lammenranta (2011) idea of the regress. An alternative view is to construe the dialectical regress to mean showing that a proposition is true. I agree to this alternative formulation. But to what end would a subject wants to show that a given proposition is true if not to be justified in holding the proposition? Ordinarily, showing that a proposition is true is a way of defending the proposition against a persistent sceptic in order to be justified in holding it. One does not only show that her beliefs are true but also want to be seen to be justified in holding them.

6. These observation conditions are given default justificatory roles due to their contextual standing in a given interaction.

7. Though Michael Williams appears to proffer an answer to the dialectical regress question; he presents his view as an alternative to some structural solutions, foundationalism and coherentism. This does not affect my criticisms of his dialectical model of justification.

8. This is common with all the dialectical foundationalist theories. Their difference perhaps lies in when and how a belief acquires this default status to end the regress. For instance, Williams is of the view that a belief acquires a default status when an interlocutor has no reasons to doubt the truth of the belief. For Leite, a belief acquires a default status when the defendant in a justificatory conversation sees no reason to doubt the truth of the belief because those beliefs are of the usual type and they are grounded in our background knowledge.

9. See the fourth mode of the Agrippa on the issue of dogmatism.

10. Recall that there are no final questions in the game of asking and giving of reasons. 
11. These papers include (Klein 1998, 1999, 2003, 2005a, 2005b, 2007a, and 2007b).

12. I employ this definition after Goldman. See Goldman, I. (1999, p. 5).

13. Adam Leite rejects models like SC1 for similar reasons as the ones listed above. He argues that it has the unpalatable consequence of relativizing individual justificatory status to the conversational participants so that a subject can be justified in holding a belief on the basis of astrological consideration if all the relevant parties in the conversation find such a belief plausible. Secondly, SC1 doesn't preserve the connection between justification and truth. And thirdly, it violates our ordinary practice of individual justification assessment endorsed by traditional epistemology. See Leite (2005). The first and third of Leite's criticisms, it seems to me, have already been addressed. I will address the second criticism later in the course of my submission.

\section{REFERENCES}

Aikin, Scott F. 2011. Epistemology and the regress problem. London: Routledge.

Alston, William. 1989. Epistemic justification. Ithaca, New York: Cornell University Press.

Annis, David B. 1978. A contextualist theory of epistemic justification. American Philosophical Quarterly, Vol. 3, pp. 213-219.

Aristotle. 1995. Posterior analytic. In Human Knowledge: Classical and Contemporary Approaches, pp. 63- 73. Edited by Paul K. Moser and Arnold van der Nat. New York: Oxford Press.

Audi, Robert. 1993. The structure of justification. Cambridge: Cambridge University Press.

Brandom, Robert. 1994. Making it explicit. Cambridge, MA: Harvard University Press. Cling, Andrew D. 2004. The trouble with infinitism. Synthese, Vol. 138, No. 1, pp. 101-123.

DeRose, Keith. 1999. Contextualism: An explanation and defense. In The Blackwell Guide to Epistemology. Edited by John Greco and Ernest Sosa, Malden, M.A: Blackwell Publishers.

Eemeren, Frans van and Rob Grootendorst. 2004. A Systematic theory of argumentation. Cambridge: Cambridge University Press.

Goldman, Alvin I. 1997. Argumentation and interpersonal justification. Argumentation, Vol. 11, No. 2, pp. 155-164.

Goldman, Alvin I. 1999. Social epistemology. Critica, Vol 31, No. 93, pp. 3-9.

Klein, Peter. 1998. Foundationalism and infinite regress of reasons. Philosophy and Phenomenological Research, Vol. 58, No. 4, pp. 919-923.

Klein, Peter. 1999. Human knowledge and infinite regress of reasons. Nous, Vol. 13, pp. 297-325.

Klein, Peter. 2003. When infinite regress are not vicious. Philosophy and Phenomenological Research, Vol. 66, No.3, pp. 718-729. 
Klein, Peter. 2005a. Infinitism's take on justification, knowledge, certainty and scepticism. Veritas, Vol. 50, No.4, pp. 153-172.

Klein, Peter. 2005b. Infinitism is the solution to the regress problem. In Contemporary Debates in Epistemology. Edited by Matthias Steup \& Ernest Sosa, pp. 131-140. Malden, MA: Blackwell Publishing.

Klein, Peter. 2007a. Human knowledge and infinite progress of reasoning. Philosophical Studies, Vol. 134, Vol.1 pp. 1-17.

Klein, Peter. 2007b. How to be an infinitist about doxastic justification. In Proceedings of the 2004 Greensboro Symposium in Philosophy (May 2007). Philosophical Studies, Vol 134, No. 1, pp. 24-29.

Lammenranta, Markus. 2011. The Pyrrhonian Problematic. In The Oxford Handbook of Scepticism. Edited by John. Greco, Oxford: Oxford University Press.

Leite, Adam. 2005. A localist solution to the regress of epistemic justification. Australasian Journal of Philosophy, Vol. 83, No.3, pp. 395-421.

Moser, Paul. 1985. Empirical justification. Dordrecht and Boston: D. Reidel.

Neurath, Otto. 1959. Protocol sentences. Logical Positivism Edited by Alfred. J. Ayer (ed.), Glencoe, IL: The Free Press

Peacocke, Christopher. 2004. The realm of reason. New York: Clarendon Press.

Pryor, James. 2000. The sceptic and the dogmatist, Nous, Vol. 34, No. 4, pp. 517-549.

Rescorla, Michael. 2009. Epistemic and dialectical regress. Australasian Journal of Philosophy, Vol. 87, No.1, pp. 3-60.

Rorty, Richard. 1979. Epistemology and the mirror of nature. Princeton: Princeton University Press.

Sextus, Empiricus. 1995. The five modes of Agrippa. In Human Knowledge: Classical and Contemporary Approaches. Edited by Moser, P. \& Vander Nat, New York: Oxford University Press.

Swinburne, Richard. 2001. Epistemic justification. Oxford: Claredon Press.

William, Michael. 1999. Scepticism. The Blackwell Guide to Epistemology. Edited by John Greco and Ernest Sosa, Oxford: Blackwell Publishing Company.

Williams, Michael. 1996. Unnatural doubts: Epistemological realism and the basis of scepticism. Princeton, NJ: Princeton University Press.

Williams, Michael. 2001. Problems of knowledge. A critical introduction to epistemology. London: Oxford University Press.

Williams, Michael. 2004. The Agrippan argument and two forms of scepticism. In Pyrrhonian scepticism. Edited by Walter Sinnott-Armstrong, Oxford: Oxford University Press.

Submitted: 27 June 2019; revised: 25 April 2020. 